\title{
DOGMÁTICA DEL HECHO PUNIBLE, PRINCIPIO DE IGUALDAD Y JUSTIFICACIÓN DE SEGMENTOS DE PENA*
}

\author{
José Milton Peralta** \\ CONICET
}

RESUMEN: Las tradicionales teorías de la determinación judicial de la pena, basadas directamente en los fines de la pena, presentan problemas de legitimación por dos razones. Por un lado, aunque dentro de una escala penal establecida, admiten un castigo que supere lo que es merecido. Por el otro, en la medida en que dentro de su lógica es perfectamente admisible castigos diferentes ante hechos iguales, violan el principio de igualdad. Con el principio de culpabilidad, la doctrina ya había intentado superar el primer escollo. El segundo, sin embargo, ha pasado un tanto inadvertido, como si se tratara de un problema menor. La distribución equitativa del castigo es parte también del castigo legítimo. Sólo determinando la pena de manera proporcional a la gravedad del hecho se puede dar cuenta de estos dos condicionamientos conjuntamente. De todas formas, para que esto no quede en un mero intuicionismo que impida el control de las decisiones judiciales, es necesario utilizar el instrumental de la dogmática del hecho punible de tradición alemana, con su consiguiente estructura sistemática. Con ella, se puede realizar un examen más preciso y minucioso de la pertinencia de los factores que hacen variar la pena y, así, asegurar la tendencia hacia una pena distribuida de manera más igualitaria.

Palabras clave: Determinación de la pena, dogmática, pena.

ABSTRACT: Traditional theories of judicial determination of the penalty, based directly on the purposes of the penalty, present legitimating problems for two reasons. On one hand, despite being within an established penalty frame, they admit a penalty that exceeds what is deserved. On the other, insofar as within their logic different penalties for equal acts are perfectly admissible, they violate the principle of equality. With the principle of culpability, doctrine had already attempted to overcome the first hurdle. The second, however, has passed relatively unnoticed, as though it were a minor problem. Equal distribution of punishment is also a part of legitimate punishment. It is only by determining the penalty proportionally to the graveness of the act that both of these requirements can be met jointly. At any rate, for this not to remain as a mere intuition hindering the control of judicial decisions, it is necessary to use the German tradition of dogmatic instruments of the punishable act, with its resulting systemic structure. With this, a more accurate and thorough examination must be undertaken of the pertinence of the factors varying the penalty and, thus, ensure the tendency towards a more equally distributed penalty.

Key words: Determination of punishment, dogmatics, punishment.

\footnotetext{
* Fecha de recepción: 28 de febrero de 2008. Fecha de aceptación: 26 de marzo de 2008.

** Doctorando por la Universidad Nacional de Córdoba, Argentina, becario Conicet, ex becario DAAD, miembro del Instituto de Argumentación Jurídica de la Universidad Blas Pascal, Córdoba, Argentina.
} 


\section{INTRODUCCIÓN}

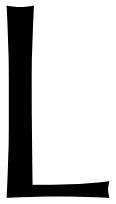

a determinación judicial de la pena es el acto jurídico mediante el cual el juez establece la cantidad de pena que le corresponde a un sujeto cuya acción se encuentra subsumida en un tipo de la parte especial. Con esta (primera) subsunción el juez cuenta ya con un marco dentro del cual puede variar la pena y su tarea consiste en establecer, dentro de ese marco, la cantidad de pena correspondiente al caso.

Una teoría de la determinación de la pena debe hacer dos cosas. Una, explicitar cuál es el trasfondo material que legitima la imposición del castigo. Esto es, tomar posición acerca del fin de la pena, sus límites y, lo que normalmente se soslaya, acerca del concepto material de delito ${ }^{1}$. Dos, especificar, de acuerdo a ello, cuáles son los factores que cuentan para esta labor concretizadora de la pena. Lo primero es, en general, lo que se debe hacer cuando se trabaja sobre cualquier instituto jurídico penal (pero no es por ello menos decisivo). Lo segundo, en cambio, es más específico de la tarea de determinación de la pena. Saber qué cuenta para determinar la pena es, justamente, el centro de la discusión y cualquier teorización que se haga al respecto debe dar cuenta de elloº

Aquí se sostiene que los modelos dominantes en relación a la determinación de la pena tienen defectos valorativos, pues desatienden un principio moral importante como el de igualdad en la distribución del castigo. Nosotros defenderemos, para superar esos problemas, una teoría de la determinación de la pena basada exclusivamente en la gravedad del hecho, entendido este como injusto (o ilícito penal) culpable.

La idea de que la pena debe corresponderse a la gravedad del hecho no es del todo nueva. Como es obvio, los retribucionistas siempre la han defendido ${ }^{3}$. Además, en la actualidad existe un «renacimiento» de la pena «justa», que tiene lugar a través de la prevención general positiva y de la que podríamos llamar «teoría de comunicación de la gravedad del hecho a su autor», defendida ahora en Alemania sobre todo por HöRNLE (1999). Esta nueva tendencia ha traído aparejado también una sofisticación de la tarea de especificación de la pena proporcional. Ambos puntos de vista, el de la prevención general positiva y el de la comunicación de la gravedad del hecho a su autor, parecen defender una teoría de la pena proporcional aparentemente por motivos no retribucionistas. Aquí, si bien se llega a las mismas consecuencias, se parte de un fundamento diferente. No es la necesidad de comunicar el reproche colectiva -o individualmentelo que fundamenta una pena proporcional, sino el hecho de que en la distribución del castigo se debe respetar el principio de igualdad, entendido éste como que a hechos iguales le corresponden penas iguales.

${ }^{1}$ En cualquier manual contemporáneo de dogmática penal se toman en serio estos problemas, pues su repercusión para ciertas estructuras dogmáticas es fundamental. Sin embargo, como se verá, a veces parece que la determinación de la pena estuviera al margen de todo esto, como si fuera un ámbito ajeno a la imposición del castigo.

2 P. S. Ziffer, 1999, Lineamientos de la determinación de la pena, 2. ${ }^{\text {a }}$ ed., Buenos Aires: Ad-Hoc, 24, 29 y ss. Si se acepta la tesis que aquí se propone, se verá que lo segundo termina siendo un reflejo de lo primero y que de ahí los problemas particulares de la determinación de la pena no serán de naturaleza distinta a los de la teoría del delito en general.

${ }^{3}$ Cfr., por todos, M. KÖHLER, 1997, Strafrecht, Allgemeiner Teil, Berlin: Springer (entre otras), 38, 577, 598 y ss. 
En lo que sigue, luego de una breve aclaración metodológica (2), se describirán y criticarán distintos modelos propuestos para determinar el contenido de una pena concreta (3). La relevancia de su repaso radica en la función dialéctica que tiene su comprensión para entender por qué se propone aquí una teoría diferente. Si el lector se encuentra al tanto de la discusión, puede pasar directamente al punto siguiente, en el que se hará un esbozo del modelo que se considera más adecuado (4). Al final, se tratará de ver la repercusión de lo postulado, a manera de ejemplo, con el problema de los motivos para delinquir (5).

\section{METODOLOGÍA}

El trabajo que se va a desarrollar es de carácter prescriptivo. No hace referencia a cómo según algún conjunto normativo se debe determinar la pena, ni tampoco a cómo lo realizan de hecho los jueces en la práctica. Se trata, por el contrario, de proponer una forma de realizar esta tarea. A efectos didácticos, podría considerarse una propuesta de lege ferenda.

Indudablemente, conforme se entiende hoy el trabajo de la dogmática, la determinación de cómo se debe aplicar la pena puede tener un reflejo en el tratamiento del Derecho positivo. En la medida que los ámbitos de indeterminación legal o lingüística lo permitan, las conclusiones a las que se llegue aquí pueden influir en la comprensión del derecho positivo. En cuanto el Derecho positivo viole premisas valorativas de carácter fundamental vinculadas a la determinación de la pena, las conclusiones a las que se arribe pueden desplazar a las determinaciones legales. Dentro de este marco, también ésta podría ser considerada una propuesta de sententia ferenda.

En cualquier caso, la vinculación entre la propuesta aquí formulada y el Derecho positivo es otra pregunta, ligada a la relación entre Derecho y moral y no necesita ser respondida aquí.

\section{MODELOS ALTERNATIVOS DE DETERMINACIÓN DE LA PENA}

Para este trabajo interesa presentar dos tipos de modelos de determinación de la pena. En el primero se consideran relevantes exclusivamente argumentos utilitaristas $(3.1)^{4}$. En el segundo tipo de modelo se agregan como factores a considerar argumentos de tipo deontológicos, que se combinan con los primeros para desarrollar teorías más respetuosas de ciertas premisas éticas (3.2). Se omite tratar aquí una propuesta de mero corte retribucionista por dos razones. Una, que en el ámbito alemán el retribucionismo es bastante parecido a lo que se denomina prevención general positiva (la que

\footnotetext{
${ }^{4}$ En el Derecho penal, cuando se hace referencia a la utilidad, se usa el término prevención y sus derivados (preventivo, prevencionista, etc.), aunque esta expresión es poco plausible en relación a algunas teorías de la pena. Con el término prevención se sugiere, pues, que la pena se dirige a la evitación de conductas delictivas, lo que no necesariamente se compadece con la idea de «devolver la paz social», «aplacar estados de indignación», etc. En cualquier caso, estas teorías no dejan de ser utilitaristas, pues pretenden generar estados placenteros (o aplacar estados de displacer). En lo que sigue, y luego de esta explicación, se usarán los términos utilidad y prevención como sinónimos.
} 


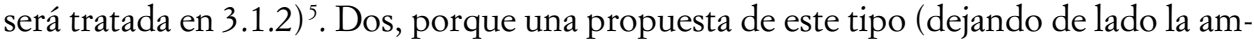
bigüedad de su carácter retributivo) tendría que conducir a un sistema similar al que se propondrá aquí, aunque el camino por el que se llegue sea diferente ${ }^{6}$. Los dos modelos que se analizarán permitirán ver una evolución histórica y argumental de los criterios de determinación de la pena hasta llegar a la pena proporcional.

\subsection{Prevención y determinación de la pena}

\subsubsection{La prevención especial en la determinación de la pena}

De acuerdo a la prevención especial, lo relevante para la medición de la pena es la peligrosidad del autor. Ésta se define como su potencialidad de volver a delinquir. La medida de la pena se establece de acuerdo a lo necesario para la reinserción social del autor (prevención especial positiva) o para su neutralización por el tiempo que fuere posible (prevención especial negativa). Conforme a una teoría bastante extendida, éste es el único factor relevante para determinar el monto de pena concreto.

Se pueden sostener tres clases de argumentos por los cuales una fundamentación de este tipo debe ser rechazada. Una de carácter empírico (a), otra de carácter sistemático (b) y una tercera clase de argumento de carácter sustancial (c).

(a) Los cuestionamientos empíricos a la prevención especial son bien conocidos. Se le achaca, en primer lugar, el fracaso rotundo de los tratamientos resocializadores ${ }^{7}$. Esta crítica es fácil de superar, renunciando a los efectos positivos de la pena y reduciendo su función a la mera inocuización del sujeto durante su período de estancia en prisión. Pero aún esta variante, la prevención especial tiene sus dificultades. Existen graves inconvenientes para realizar pronósticos de peligrosidad lo suficientemente serios que permitan justificar la privación de la libertad por un determinado espacio de tiempo ${ }^{8}$.

(b) Los argumentos de carácter sistemático se dirigen a destacar los efectos que una determinación de la pena basada en la prevención especial debería tener sobre el sistema de un código penal y sobre la misma teoría del delito. Las escalas penales no tienen sentido como han sido fijadas (en relación a la gravedad del hecho) y tampoco tiene sentido siquiera su existencia: la peligrosidad es demasiado individual como para hacer generalizaciones de esta clase. Ciertas atenuantes, como la del 81 inc. $1 \mathrm{CP}$ argentino o 21.1 del CP español, no se explican en un sistema basado en la peligrosidad e, incluso, la idea misma de que sea necesaria la comisión de un delito para imponer una pena se torna cuestionable ${ }^{9}$. Sólo se puede dar cuenta de ello si lo que cuenta para el «sí» de la pena no es lo mismo que cuenta para el «cuánto». De otra forma, los «hechos» relevantes para dar paso a la pena deberían ser distintos de los que normalmente se tienen en cuenta e incluirse, por ejemplo, modos de vida ${ }^{10}$.

5 B. Schünemann, 2002, Aporien der Straftheorie in Philosophie und Literatur, en PRITWITZ (entre otros) (comp.), homenaje a Lüderssen, Baden-Baden: Nomos, 327, 328 y ss.

${ }^{6}$ Así también, T. HöRnLe, 1999, Tatproportionale Strafzumessung, Berlin: Duncker \& Humblot, 18.

Cfr., entre otros, W. HASSEMER y F. MuÑOz CONDE, 2001, Introducción a la criminología, Valencia: Tirant lo blanch, 243 y ss.

${ }^{8}$ B. FEIJOO SÁNCHEZ, «Individualización de la pena y teoría de la pena proporcional al hecho», en Indret 1/2007, www.indret.com, 13.

9 KÖHLER (n. 3), 41. H. H. LESCH, 1994, «Zur Einführung in das Strafrecht: über den Sinn und Zweck staatlichen Strafens (2.Teil)», JA, 590 y ss.

${ }^{10}$ Cfr. respecto del concepto material de delito, C. Roxin, 2006, Strafrecht Allgemeiner Teil, t. I, München: C. H. Beck, 2/1 y ss. NúÑ̃Z es felizmente explícito respecto de esta dicotomía. Para él existe un dualismo «cul- 
Por otro lado, las finas elaboraciones dogmáticas que pretenden tener repercusión a nivel valorativo, es decir, en el monto de la pena, se vuelven prácticamente irrelevantes, si la determinación de la pena no tiene ninguna base en ellas. Cuestiones como la diferencia entre dolo directo y eventual, culpa conciente e inconciente, tentativa acabada e inacabada, etc. no tienen que ver con la peligrosidad del sujeto ${ }^{11}$.

Algunos autores, en un intento de rescatar a la prevención especial, afirman que de lo que se trata, en realidad, es de una necesidad preventivo-especial «que surja del "hecho" cometido» ${ }^{12}$. Pero esto constituye una deformación del lenguaje ${ }^{13}$. Peligrosidad no es lo mismo que gravedad del hecho ${ }^{14} \mathrm{y}$, por ende, no necesariamente quien comete un hecho grave es un sujeto peligroso en esa intensidad ${ }^{15}$.

(c) Las críticas mencionadas a la determinación de la pena en base a las necesidades preventivo-especiales revisten un carácter subsidiario. Ellas presuponen, pues, la legitimidad de ese fundamento como determinante para fijar la pena. Sólo tiene sentido preguntarse por su corroboración empírica o coherencia con otros institutos de Derecho penal si previamente se ha respondido «sí» a la pregunta sobre su legitimidad como factor determinante de la pena. El tercer tipo de argumento crítico trata sobre la incorrección moral de esa fundamentación.

Una pena determinada en base a la prevención especial viola la autonomía de los individuos, porque implica castigar al sujeto por cuestiones en las que el Estado no tiene derecho a intervenir: la vida no delictiva del autor ${ }^{16}$. Más allá de los problemas que existen para determinar la peligrosidad del autor, ésta se va a basar, necesariamente, en datos de la realidad de entre los cuales el hecho sólo es uno más. El resto estará vinculado a los hábitos pasados y los futuros planes de vida posibles del autor. La otra cara de la moneda de una pena basada así es, pues, que se alientan ciertos modos de ser frente a otros, lo que un Estado liberal no puede permitir.

Una pena en base a estos criterios admite, además, imponer penas por encima del merecimiento ${ }^{17}$, violando así un principio extendido que dice que el castigo no debe superar lo que es retribuible ${ }^{18}$. En efecto, si el delito cometido sólo cuenta como un dato que revela la peligrosidad del autor, pero luego de una investigación surge que en realidad el sujeto es

pabilidad-peligrosidad», por lo que hay que dividir el fundamento de la responsabilidad penal de su medida. «[L]os factores objetivos como tales [...] sólo actúan en el ámbito de la individualización judicial de la pena como puntos de arranque o medios para determinar la base subjetiva de la misma». Entendiendo por factor objetivo el ilícito y por factor subjetivo «la mayor o menor probabilidad de volver a delinquir» del delincuente ( $\mathrm{R}$. NúÑEZ, 1965, Derecho penal argentino, t. II, Córdoba: Lerner, 1965, 457 y ss.)

${ }_{11}$ G. STRATENWERTH, 1971, «Tatschuld und Strafzumessung», en Recht und Staat, Herft 406/407, Tübingen: J. C. B. Mohr, 27; también HöRNLE (n. 6), 70.

${ }_{12}$ C. RoXIN, 2003, Strafrecht Allgemeiner Teil, t. II, München: C. H. Beck, 30/6; similar KÖHLER (n. 3), 46; E. R. ZAFFARONI, A. y A. SlOKAR, 2002, Derecho penal, parte general, 2. ${ }^{a}$ ed., Ediar, 1045. Esta tendencia quizás provenga de las afirmaciones del propio LIsZT, pues éste, en las primeras ediciones de su obra hacía lo mismo, $c f r$., al respecto, E. BACIGALUPO, 1999, Delito y punibilidad, 2. ${ }^{a}$ ed., Buenos Aires: Hammurabi, 83 y ss.

${ }^{13}$ También ZIFFER (n. 2), 66.

${ }^{14}$ KÖHLER (n. 3), 41 y ss.

15 W. HASSEMER, 1976, «Strafzumessung, Strafvollzug und die, Gesamte Strafrechtswissenschaft», en LÜDERSSEN/SACK (comp.), Seminar: Abweichendes Verhalten II Die gesellschaftliche Reaktion auf Kriminalität, Frankfurt: Suhrkamp, 243, 245; D. BAIGÚN, 1971, Naturaleza de las circunstancias agravantes, Buenos Aries: Pannedille, 1971, 83; BACIGALUPO (n. 12), 83

${ }^{16}$ HÖRNLE (n. 6), 40 y ss., 49 y ss. Se trata de una forma encubierta de valorar la «conducta de vida» del autor.

${ }_{17}$ KÖHLER (n. 3), 48 y ss. En contra BACigAluPo (n. 12), 200, para quien es suficiente con que el autor conozca que será sancionado, sin que la dimensión de la sanción sea relevante.

18 A. von HiRsCH, 1976, Doing Justice, New York: Hill and Wang, 5; H. L. A. HaRT, 1968, «Prolegomenon to the Principles of Punishment», en ID, Punishment and Responsibility, Oxford: Clarendon, 26 y ss; P. ZIFFER, 2002, «comentario arts. 40 y 41 CP» en, BAIGÚN y ZAFFARONI (dirs), Código comentado, Buenos Aires: Hammurabi, 65. 
mucho más peligroso de lo que el hecho indicaba, nada impide, conforme a este parámetro, imponerle una pena más elevada que lo que el hecho merecía.

Obviamente, esto es más sutil que establecer prohibiciones a ciertos modos de ser o sancionar conductas que no merecen castigo, pero la diferencia es solamente de grado ${ }^{19}$.

De todos modos, no es sólo al Derecho penal peligrosista a lo que debe temer un Derecho penal que quiera realizar ciertos principios morales que le otorguen legitimidad. La prevención general también puede conducir a ciertas consecuencias inaceptables.

\subsubsection{La prevención general en la determinación de la pena}

Según la teoría de la prevención general, la justificación de la pena reside en que ella influye sobre un número indeterminado de individuos logrando efectos útiles en la sociedad. En su variante «negativa», este efecto se logra porque la pena les proporciona a los potenciales autores razones prudenciales para no delinquir (prevención general negativa). En su versión «positiva», la sanción cumple dos funciones. Por un lado, se influye sobre la sociedad mejorando la internalización de los valores cuestionados por la conducta delictiva. Por el otro, se reestabiliza a una sociedad conmocionada por el hecho delictivo, logrando así un efecto de pacificación ${ }^{20}$. No corresponde aquí emprender una tarea de explicación o justificación de alguna de estas funciones o fines de la pena ${ }^{21}$. Lo importante es, para lo que aquí interesa, que todos estos fines, tantos los de la prevención general positiva como los de la negativa, tienen un carácter utilitarista, se dirigen a una sociedad concreta y su satisfacción depende de algo constatable empíricamente. Lo que se debe comprobar es qué pena es necesaria para lograr estos efectos que se pretenden.

Si la prevención general, en cualquiera de sus variantes, debe guiar la medición de la pena, el juez debe realizar, en el caso concreto, esa tarea de evaluación de necesidad de pena. Es decir, deberá apreciar cuánta pena requiere el caso que tiene al frente, para satisfacer esas necesidades preventivas.

Se pueden ensayar tres críticas a una argumentación que afirme que el juez debe determinar la pena de esta manera, también caracterizables como (a) empíricas (b) sistémicas y (c) morales.

(a) El juez no está en condiciones de hacer el tipo de evaluación que requiere la prevención general, pues carece, debido a la forma en que está estructurada su actividad, del «termostato» social adecuado para medir la necesidad de pena. Su decisión será, por ello,

19 A. VON HirSCH/N. JAREBORG, 1991, «Gauging Criminal Harm: A Living-Standard Analysis», en Oxford Journal of Legal Studies, 11, Oxford University Press, 35; sobre el problema también J. M. SILVA SÁNCHEZ, 2007, «La teoría de la determinación de la pena como sistema (dogmático): un primer esbozo», InDret/2, (www.indret.com), 01 y ss.

${ }^{20}$ Cfr. Roxin (n. 10), $3 / 26$ y ss.; G. JAKOBS, 1993, Strafrecht Allgemeiner Teil, 2. a ed., Berlin-New York: de Gruyter, 1/4, 11 y ss., 15-16. ID, «Das Strafrecht zwischen Funktionalismus und "alteuropäischem” Prinzipiendenken», ZStW 107 (1995), 843, 865. ID, «Über die Behandlung von Wollensfehlern und von Wissensfehlern», ZStW 101 (1989), 516, 517

${ }^{21}$ Con más detenimiento sobre la prevención general positiva ver J. PERALTA, Prevención general positiva como respeto por el orden jurídico, Indret, 2/2008 (www.indret.com). 
normalmente «parcial e irracional» 22 . Por otro lado, es muy difícil demostrar cómo las pequeñas variaciones de pena que puede realizar juez, dentro del marco penal determinado por el legislador, pueden influir en conductas futuras de los ciudadanos ${ }^{23}$.

De todos modos, si bien esto es cierto por regla general, hay casos en lo que esta crítica no resulta del todo convincente. Si bien, normalmente, el juez no puede hacer una meritación de las necesidades de pena y debe conformarse con seguir al legislador, existen casos en los que debido a la gran publicidad que se le brinda por la prensa sumado al amplio marco de que dispone el juez para graduar la pena, es posible que logre objetivos preventivo generales imponiendo ciertos montos de pena, a pesar de las limitaciones mencionadas.

(b) Los problemas sistemáticos que surgen de considerar estos factores para la determinación de la pena son similares a los que se plantearon respecto de la prevención especial. Las categorías delictivas, cuidadosamente refinadas por los científicos del Derecho, pierden su lugar ante la percepción real de la sociedad. «Fin de la norma», «prohibición de regreso», «incremento del riesgo», etc. son institutos que poco tienen de comunicables masivamente. Más bien, parece que sucede lo contrario. Que el apego a ciertas premisas que justifican el castigo resulta irritante para una población que no las comprende. Se puede alegar que no se trata, en realidad, de los efectos que la pena pueda tener en una sociedad concreta, sino en una «completa y exactamente informada» ${ }^{24}$. Pero esto ya no es prevención general, sino otra cosa ${ }^{25}$.

(c) Decisivo, no obstante, es otra vez el punto deontológico. La medición de la pena basada en la prevención general puede justificar castigos por encima del merecimiento.

Existe abundante literatura que confía en que la prevención general positiva puede garantizar una pena justa ${ }^{26}$. Así, se dice que si no se respetara la proporcionalidad de las penas se produciría una reacción negativa de la sociedad hacia el Derecho ${ }^{27}$ y que, por ende, sería disfuncional ${ }^{28}$. Sin embargo, sólo puede afirmarse por regla general que una pena adecuada a la responsabilidad que tiene el autor cumplirá las funciones preventivas con total eficacia, pues esto, por ser algo que debe verificarse empíricamente, es necesariamente contingente ${ }^{29}$. El tratamiento dado por la prensa o la impresión que da el autor en la sociedad, la gravedad del daño no imputable al riesgo generado conducta, etc., pueden conducir a una pena excesiva desde el punto del merecimiento individual ${ }^{30}$. En efecto, para cumplir los fines de la prevención general negativa, nada mejor que imponer penas más intensas conforme la inseguridad va aumentando. Aquí también es cierto que llevado al extremo sería inaceptable un sistema que imponga penas excesivas, pero nada excluye uno que admita ello en ciertos casos concretos, si es que el juez puede basar la pena en estos criterios ${ }^{31}$.

${ }_{22}$ M. GARCíA ARAN, 1981, «La prevención general en la determinación de la pena», en ADPCP, 516; T. HöRnle, 2003, Determinación de la pena y culpabilidad, Buenos Aries: Di Plácido, 25; W. HASSEMER, 1979, «Generalprävention und Strafzumessung», en HÖRNLE/LÜDERSEN/NAUCKE, Hauptprobleme der Generalprävention, Frankfurt/Main: Metzger, 29, 41 y ss.; FEIJOO SÁNCHEZ (n. 8), 13 con referencias ulteriores.

23 GARCía Aran (n. 22), 517.

${ }^{24}$ BGHSt (sentencias del Tribunal Supremo Alemán en asuntos penales) 24, 63, 69

25 En realidad, bastante difícil de precisar. Parece más bien una especie de retribución encubierta bajo argumentos preventivos. Este problema merece un análisis más detenido que no se puede realizar en este lugar.

${ }^{26}$ Cfr., por todos, P. NolL, 1965, «Schuld und Prävention unter dem Gesichtspunkt der Rationalisierung des Strafrechts», en GEERDS/NAUCKE (comps.), Beitrage zur gesamte Strafrechtswissenschaft, homenaje a Mayer, Berlin: Dunker \& Humbolt, 223; distanciadamente A. AsHWORTH, 2003, Principles of Criminal Law, 4. ${ }^{\mathrm{a}}$ ed., Oxford: Oxford University Press, 21.

27 HART (n. 18), 25.

${ }^{28}$ FRISCH (n. 52), 7.

${ }^{29}$ HAssemer (n. 22), 33; HÖRNLE (n. 6), 92 y ss.

30 HÖRNLE (n. 6), 208.

31 El Tribunal Supremo alemán, de hecho, ha admitido eso en algunos casos expresamente, afirmando que es posible superar la pena correspondiente a la culpabilidad cuando amenace «un aumento de hechos como el 
En relación a la prevención general positiva, la situación no es diferente. Aquí también la necesidad de confirmar valores sociales o de satisfacer el reclamo popular de justicia puede llevar a resultados injustos. La idea de que prevención y justicia van de la mano tiene más que ver, como afirma FLETCHER, en realidad, con la necesidad de ajustar la prevención a ciertos criterios de justicia, que a que entre ambas exista una relación de nece$\operatorname{sidad}^{32}$.

\subsection{Culpabilidad y prevención en la determinación de la pena}

La ausencia de una correlación necesaria entre culpabilidad y prevención ha conducido a la construcción de teorías que se preocupan por aunar ambos conceptos, combinándolos. Se busca, de esta manera, legitimidad, a través del respeto de la culpabilidad, y eficacia, dando lugar a finalidades preventivas sin violar aquélla.

\subsubsection{La teoría del espacio de juego}

La teoría del «espacio de juego» o «margen de libertad» (Spielraumtheorie), fundada en Alemania por A. F. BERNER en el siglo XIX y desarrollada, principalmente, por el Tribunal Supremo alemán ${ }^{33}$, tiene extendida aceptación entre los científicos. Según esta teoría, una pena adecuada a la culpabilidad por el hecho admite, dentro de ciertos márgenes, que se tengan en cuenta consideraciones preventivas. Esto es posible gracias a la indeterminación de la que padece la idea de culpabilidad (entendida como proporcionalidad) que carece de contornos precisos. Existe, entonces, un «espacio de juego» (Spielraum) en el que se puede pensar una pena un poco menor «ya adecuada a la culpabilidad» y una pena un poco mayor «todavía adecuada a la culpabilidad» ${ }^{34}$. Dentro de ese marco, pueden considerarse argumentos de prevención especial o general, según el caso.

Una objeción que se formula en contra de la teoría del espacio de juego es que la indeterminación que fundamenta la apertura de ese marco se repite en los contornos que lo delimitan ${ }^{35}$. Para solucionar esto, las zonas de penumbra se deberían reducir refinando los dos factores que cuentan para la pena. Pero el problema es que ambos fac-

que se está condenando u otros similares, cuando resulten peligrosos para la sociedad». Cfr. H. H. JESCHECK y T. WeIgend, 1996, Lebrbuch des Strafrechts, Allgemeiner Teil, Berlin: Duncker \& Humbolt, 5. Auf., 882.

32 G. P. FletCHER, 1988, «Utilitarismus und Prinzipiendenken in Strafrecht», ZStW 101, 803, 817.

33 BGHSt (sentencias del Tribunal Supremo Alemán), t. 7, 28 y ss.

34 F. SCHAFFSTEIN, 1973, Spielraum-Theorie, Schuldbegriff und Strafzumessung nach den Strafrechtsreformgesetzen, homenaje a Gallas, Berlin-New York: de Gruyter, 99 y ss.; H. J. Bruns, 1974, «Alte Grundfragen und neue Entwiclungstendenzen im modernen Strafzmessungsrecht», en Stratenwerth, entre otros (comp.), homenaje a Welzel, Berlin-New York: de Gruyter, 744 y ss.; Roxin, 1977, «La determinación de la pena a la luz de la teoría de los fines de la pena», en ID, 1981, Culpabilidad y prevención, trad. de Francisco Muñoz Conde, Madrid: Reus, 1981, 93, 97 y ss.; ID, 1978, «Prevención y determinación de la pena», en ID (cita anterior), 115, 116 y ss.; B. SCHÜNEMANN, 1995, «La función del principio de culpabilidad en el Derecho penal preventivo», en $E l$ sistema moderno del Derecho penal: Cuestiones fundamentales, el mismo (comp.), Madrid: Tecnos, S. 147: 172

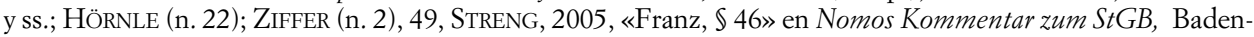
Baden: Nomos, 1402, 1453 y ss.

35 ZIFFER (n. 2), 54 
tores son extremadamente difíciles de refinar. Tanto la culpabilidad ${ }^{36}$ como las necesidades de prevención se manejan sólo en un ámbito especulativo, lo que conduce a que la zona de penumbra de la pena no pueda ser reducida satisfactoriamente.

Sin embargo, esta construcción tiene el mérito de haber dicho claramente que es plausible encontrar distintas penas adecuadas a la culpabilidad, pero que también existen penas que no pueden ser ubicadas dentro de ese marco. Por ende, con ella se reduce notablemente el margen de discrecionalidad para determinar la pena ${ }^{37}$.

De todas formas, aún se pueden enumerar tres inconvenientes de una construcción como esta. El primer problema es que si bien en esta teoría ciertas diferencias valorativas se tornan relevantes, en la medida en que hay un «espacio de juego» las categorías valorativas derivadas de la dogmática pierden un poco su valor. En este sentido, las críticas de carácter sistemático hechas a las teorías exclusivamente preventivas también se pueden dar aquí por repetidas, aunque con menor fuerza. El segundo escollo es que si sólo hay un espacio de juego, se tiene que conceder que aunque no haya necesidades preventivas, la pena siempre se puede fundar exclusivamente en la culpabilidad ${ }^{38}$, con lo que se (re)caería en un retribucionismo difícil de compatibilizar con un estado liberal. Como se verá al analizar la teoría de la pena proporcional, este problema se puede solucionar sin recurrir a argumentos retributivos, pero esta empresa no ha sido encarada por los defensores de esta teoría. Por el contrario, en respuesta a esta última dificultad surge la teoría de la culpabilidad sólo como límite máximo. Finalmente, esta teoría tiene una debilidad que también comparten la teoría que sigue y todas las teorías preventivas mencionadas. Todas ellas admiten que ante hechos iguales se sancione de manera diferente, vulnerando de esta forma el principio de igualdad. Luego de analizar la siguiente construcción se verá el problema con más detalle.

\subsubsection{La culpabilidad como límite máximo}

Esta teoría es una modificación de la del espacio de juego. Aquí se admiten también diferentes montos de pena que se adecuen a la culpabilidad, pero, mientras la teoría del espacio de juego no acepta una pena que no se corresponda con el merecimiento, la que estamos presentando ahora sí, siempre que sea por debajo.

La culpabilidad debe funcionar sólo como un límite máximo. Esto es así, se dice, porque la culpabilidad no fundamenta la pena, sino que sólo la legitima. El único fin de la culpabilidad es demarcar hasta dónde el castigo es aceptable ${ }^{39}$. Éste será legítimo sólo en la medida en que el hecho le pueda ser retribuido al sujeto. Por el contrario, y puesto que la culpabilidad no fundamenta el castigo, se puede imponer una pena por deba-

36 STRENG (n. 34), 1454. Sobre todo atento a la falta de claridad respecto de qué signifique esto, cfr. HöRNLE (n. 6), 38 ss.

37 En el mismo sentido HöRnLE (n. 6), quien destaca la funcionalidad de este punto para el juez que resuelve en casación.

38 SCHAFFSTEIN (n. 34), 105 y 108.

39 Roxin, 1993, Das Scbuldprinzip im Wandel, homenaje a Arthur Kaufmann, Müller: Heidelberg, 519, 523; SCHÜNEMANN (n. 34), 171 y ss. y 178; M. H. BORINSKY, 2001, «El concepto de peligrosidad del art. 41 del $\mathrm{CP}$ y su confronte con el derecho penal de acto (art. 19 de la $\mathrm{CN}$ ) a los fines de la determinación de la pena», en www.eldial.com (suplemento penal, sección doctrina), 13. 
jo de ese límite. El límite mínimo lo pone, en este caso, la necesidad de pena ${ }^{40}$. De ello se sigue que una pena que no esté fundamentada de acuerdo a ambos factores no será una pena moralmente aceptable ${ }^{41}$. Cada uno de ellos funciona como condición necesaria, pero no suficiente ${ }^{42}$. El defensor más conocido de esta postura es RoXIN, quien afirma que si la prevención especial indica una pena inferior a la culpabilidad, se debe hacer lugar a aquélla, y sólo debe ceder en situaciones excepcionales «cuando la imposición de una pena inferior a la que corresponda por el grado de culpabilidad <parezca simplemente como incomprensible para la sensibilidad jurídica general ${ }^{43}$. Con ello RoXIN señala que el límite mínimo también está marcado por la prevención, sólo que en este caso general positiva. De lo dicho se sigue que, en el caso de que no existieran necesidades preventivas, esta teoría debería conducir a la ausencia de pena ${ }^{44}$.

ZAFFARONI podría ser incluido también dentro de una concepción como ésta. Si bien no la sigue exactamente, constituye un caso en el que la culpabilidad hace de límite máximo de la pena ${ }^{45} \mathrm{y}$ donde otros factores pueden conducir a que la pena se imponga por debajo de aquélla.

La culpabilidad (en el sentido de proporcionalidad) es el primer factor determinante de la pena, como lo es también para Roxin y, al igual que para éste, se puede imponer una pena por debajo de ella. Pero el factor que es decisivo para hacer esa reducción es completamente distinto. El segundo factor que cuenta en ZAFFARONI para la determinación de la pena es «el esfuerzo personal por la vulnerabilidad». Esto es algo así como el empeño que ha puesto un sujeto para ser atrapado por un sistema que es eminentemente selectivo ${ }^{46}$. A mayor susceptibilidad de ser elegido por el sistema (por el lugar donde se vive, el aspecto físico, la formación, etc.), por regla general, menor esfuerzo habrá hecho el sujeto para ser seleccionado y viceversa. Por supuesto, se trata de un esfuerzo figurado para ser atrapado por el sistema, esto es, de un concepto eminentemente normativo. Una vez precisados muy someramente ambos factores surge el concepto de culpabilidad que será decisivo para la medición de la pena. En palabras de ZAFFARONI «[L]a culpabilidad importa un proceso valorativo dialéctico, en el que acaban sintetizándose la reprochabilidad por el acto [culpabilidad] (que prescinde de la selectividad y, por ende, de la vulnerabilidad), y un cálculo del esfuerzo que el agente haya hecho por alcanzar la situación concreta de vulnerabilidad al poder punitivo (culpabilidad por la vulnerabilidad), resultando de ambas culpabilidades (por el acto y por la vulnerabilidad) la culpabilidad normativa» ${ }^{47}$.

A esta teoría se le pueden formular ciertas críticas comunes las de la culpabilidad como límite máximo de Roxin, pero conviene ahora detenerse en una que se relacionada concre-

${ }^{40}$ Dicha necesidad también hace, en otro sentido, las veces de límite máximo, pues cualquier monto de pena que supere el límite puesto por la necesidad será ilegítimo, porque se estaría imponiendo sin ninguna justificación utilitarista.

${ }^{41}$ Cfr. SCHÜnemann, 1995 (n. 34), 173; M. Clark, 1971, «The Moral Graduation of Punishment», en The Philosophical Quarterly, vol. 21, n. ${ }^{\circ} 83,132,135$. De todos modos CLARK admite que, en ciertos casos especiales, se supere el límite de lo «merecido» atendiendo a razones de prevención, 135.

${ }^{42}$ En cualquier caso, si el límite mínimo que marca la necesidad supera el límite máximo demarcado por la culpabilidad, prevalecerá la pena determinada conforme a esta última. De otra forma, la pena no sería legítima.

${ }^{43}$ ROXIN (n. 34), 109 y ss. En el mismo sentido se pronuncia, desde el lado anglosajón, CLARK. Para él también la utilidad debe marcar un límite máximo, de otra forma «se superaría lo que es necesario para lograr fines utilitaristas» (n. 41), 139.

${ }_{44}$ Así es como de hecho fundamenta Roxin la exclusión de pena en las causas de exculpación. Cfr. (n. 10), 19/1 y ss., 22/1 y ss. Cfr., también, la crítica de KÖHLER (n. 3), 41.

${ }^{45}$ ZAFFARONI (n. 12), 1035.

46 La selección es hecha de acuerdo a ciertos esteriotipos criminales y, por regla general, por la policía, ZAFFARONI (n. 12), 7 y ss. y 1055.

47 ZaFFARONI (n. 12), 1032 en cursiva en el original. 
tamente con ésta. ¿Por qué podría ser este figurado esfuerzo por la selectividad un factor relevante para la medición de la pena? Esto sin duda puede indicar una mayor necesidad de pena desde un argumento preventivo. Así, si un funcionario público comete un hurto en un supermercado y eso trasciende por la prensa, se puede esperar un reclamo popular de mayor castigo que el que corresponda a un ciudadano que no reúna esas características (aunque esto no esté justificado). Pero esto es obviamente lo que no quiere ZAFFARONI, pues este autor se autodenomina un «agnóstico» de la pena ${ }^{48}$. No es fácil encontrar otra fundamentación plausible partiendo de sus premisas, pues, siendo un agnóstico de la pena y sosteniendo que la única función legítima de la actividad judicial radica en limitar el poder punitivo irracional, no puede afirmarse que en estos casos se deba imponer una pena más grave que en los casos de sujetos más vulnerables. De otra forma, lo que se está diciendo es que en esos casos es necesario aplicar más pena y eso requiere legitimidad y que la pena cumpla una función. Si esto no se quiere decir, entonces, en estos casos también se deberá intentar poner freno al poder punitivo y procurar en lo posible que se imponga el mínimo de la pena (o, más coherentemente, que no se imponga pena en absoluto).

Existe otra interpretación posible de lo que dice ZAFFARONI, y es que su afirmación no tenga un carácter prescriptivo, sino descriptivo. Eso se puede ver en el siguiente pasaje: «sólo en un sentido bastante metafórico puede entenderse como el reproche por el Esfuerzo personal, pues en definitiva ese juicio no hace más que medir el límite del poder de contención del Derecho penal en caso concreto» ${ }^{49}$. Esto, claramente, no es lo que ZAFFARONI había dicho antes, pero, en todo caso, semejante afirmación carece de valor para la dogmática (tal como se la entiende corrientemente). De una descripción, como se sabe, no se sigue nada. También se puede describir que el sistema castiga más a los más vulnerables, sin que de eso se siga que deba ser así.

Parece, en realidad, que ZAFFARONI pretende hacer una suerte de discriminación inversa con el dDerecho penal, castigando más a los que menos suele seleccionar el sistema. Pero emprender semejante tarea ;con el Derecho penal! es inaceptable, pues implica hacer responsable penalmente a las personas por algo que no es legítimo que se les cargue: ser blancos, tener dinero, no tener rasgos indígenas, vestir bien, en síntesis, no ser vulnerables. Y esto no deja de ser relevante sólo porque, de todas formas, no se rebase la culpabilidad por el acto. Se está diferenciando entre dos sujetos por algo de lo que ellos no son responsables. La forma de eliminar la discriminación que existe actualmente en la práctica del Derecho penal es haciendo siempre, a los vulnerables y a los no vulnerables, sólo responsables por el acto realizado, sin considerar otro factor. Y esto ya emparenta esta teoría con el resto que combinan culpabilidad y prevención.

El asunto central es si es admisible considerar factores independientes al hecho como determinantes de manera autónoma para la fijación de la pena, de manera tal que dos sujetos que hacen lo mismo reciban penas diferentes sólo por cuestiones preventivas ajenas a su conducta ${ }^{50}$. Una pena no sólo puede chocar contra ciertas premisas deontológicas porque supere el margen de la culpabilidad, sino también cuando se impone por debajo de ésta, si lo que se tiene en cuenta como factor determinante para hacer la distinción es un factor por el que no se puede responsabilizar al sujeto ${ }^{51}$. Si esto es correcto, de lo que se trata es de si no corresponde introducir todavía un tercer factor relevante para la determinación de la pena: la distribución equitativa del castigo.

\footnotetext{
48 ZAFFARONI (n. 12), 28 ss. y 44 ss.

49 ZAFFARONI (n. 12), 1045.

${ }^{50}$ VON HirSCH (n. 18), 64; STRENG (n. 34), 1455.

51 En contra, por todos, Roxin (n. 34), 135 y ss.
} 


\section{EL PRINCIPIO DE IGUALDAD Y LA TEORÍA DE LA PENA PROPORCIONAL}

Presupuesto del análisis realizado hasta ahora es, entonces, la utilidad de la pena. La institución del castigo, en un Estado secular, sólo está justificada en la medida en que cumpla una función en la sociedad. Conclusión de lo mencionado es que esa utilidad no puede ser lograda de cualquier modo. El castigo precisa de una legitimidad moral y, por ello, no debe superar el límite de la culpabilidad. Ésta es un condicionamiento deontológico a los fines sociales del castigo.

Sin embargo, también se advirtió que estos dos elementos parecen no ser suficientes para que la práctica del castigo sea legítima. Una premisa esencial es que el castigo sea distribuido también de manera equitativa ${ }^{52}$, de tal manera que no se viole el principio de igualdad, condición esencial de la justicia del trato que reciben los individuos por parte del Estado.

Los individuos tienen el derecho a ser tratados todos por igual y la violación a estos principios les permite elevar un reproche en contra de la autoridad que no lo respeta. Si bien la igualdad no abarca todo el concepto de justicia, «sin ella no se puede discutir la justicia en absoluto» ${ }^{53}$. El hecho es que no sólo cuando se castiga por encima de la culpabilidad, sino también cuando se sanciona por debajo de ella se está atentando contra un principio moral que legitima el castigo ${ }^{54}$. «[P] recisamente conforme al principio de igualdad, [se justifica] — dice FERRAJOLI — la graduación equitativa de la medida de la pena, para cada hecho singular...» ${ }^{55}$. Es decir, no sólo se debe respetar la «proporcionalidad cardinal», contenida en el principio de culpabilidad, sino también la «proporcionalidad ordinal», contenida en el principio de igualdad ${ }^{56}$.

La primera crítica que se podría plantear es que si esto se toma en serio no habrá ninguna diferencia práctica entre los casos y la forma en la que está dispuesto a castigar un retribucionista y los casos y la forma en la que nosotros estaríamos dispuestos a castigar, por lo que todo esto no pasaría de ser un retribucionismo encubierto ${ }^{57}$. Penar de acuerdo a criterios de justicia distributiva no significa, empero, ser retribucionista. Significa, por el contrario, distinguir entre dos factores que pueden funcionar de manera independiente en la institución de la pena: justificación general del castigo y for-

${ }^{52}$ HaRT (n. 18), 11. Una de las críticas más comunes a los modelos preventivos, es, como se analizó detalladamente y analíticamente más arriba, que permiten un castigo injusto. Cfr., al respecto también, W. FRISCH, 2003, «Einleitung-Hintergrund, Grundlinien und Probleme der Lehre von der tatproportionalen Strafe», en FRISCH/VON Hirsc/AlbReCHT (comp.), Tatproportionalität, C. F. Müller, 1, 1 y ss. La pena basada en las necesidades preventivas «es sentida por muchos como poco transparente, para no decir arbitraria, irregular e injusta...».

53 Fletcher (n. 32.), 803, 808.

${ }^{54}$ Clark (n. 41), 132 y ss. a pesar de que este autor admite excepciones, 139.

55 L. Ferrajoli, 2001, Derecho y razón, Teoría del garantismo penal, 5. ed, Madrid: Trotta, 404; también FRISCH (n. 52), entiende que este es uno de los fundamentos de la pena proporcional, p. 2.

${ }^{56}$ Sobre esto VON HIRSCH, 1991, «Proportionality in the Philosophy of Punishment: from "Why punish?" to "How much?” », HeinOnline, Israel Law Review, 549, 572 y ss; A. AsHWORTH, «Kriterien für die Proportionalität der Strafe», en FrisCHVON HiRSC y AlbeCHT (n. 52), 83 y ss.

57 Lo que de hecho tampoco sería exacto. Pues aquí se trata siempre de una justicia relativa que se mide de acuerdo a su forma de distribución (HöRNLE habla de una proporcionalidad relativa, [n. 6], 155 y ss.). Si la ausencia de necesidad de pena permite que la rigurosidad del castigo penal remita a formas menos dolorosa, mientras esto sea hecho respetando la igualdad, será un «avance» bienvenido. Un retribucionista quizás no esté dispuesto a tolerar tal remisión. 
ma de aplicación ${ }^{58}$. «[...] es perfectamente consistente», señala HART, «afirmar ambos, que el objetivo general que justifica una práctica sancionatoria son sus consecuencias benéficas $y$ que el propósito de ese objetivo general debe ser limitado o restringido respetando los principios de la distribución.... ${ }^{59}$. Esto es, en realidad, lo que ya viene haciendo en la dogmática del hecho punible con el principio de culpabilidad. Es sólo que hay que introducir un elemento más. Además de no superar la proporcionalidad del castigo, es necesario que la distribución sea equitativa ${ }^{60}$.

Quien con más fuerza ha tratado de llevar a cabo este programa propuesto por HART ha sido VON HIRSCH en la obra ya citada Doing Justice ${ }^{61}$. Este autor se ha esforzado por mostrar cómo la pena debe ser distribuida conforme a criterios retributivos, reconociendo incluso que la justificación general del castigo (sea ésta de prevención general positiva o negativa) es relativamente indiferente para la determinación de la pena ${ }^{62}$. En el mismo sentido se pronuncia HÖRNLE, quien también continúa esta línea de trabajo, ya refiriéndose sólo a la determinación judicial de la pena. La «...explicación general del castigo criminal como una institución, [afirma] no tiene relevancia...al condenar» ${ }^{63}$. De todos modos, nuestras coincidencias con estos autores son, en principio, sólo respecto del resultado: pena proporcional conforme a ciertos criterios, a desarrollar, contrastables. Pero el fundamento es diferente. Mientras VON HIRSCH y HöRNLE hacen hincapié en la comunicación que la pena proporcional ejerce sobre el penado, apelando a su razón para que comprenda el disvalor de su acción ${ }^{64}$, aquí se trata de algo diferente. Se trata sólo de que la pena es, materialmente, un dolor, un sufrimiento impuesto deliberadamente y que, por ello, debe ser distribuido conforme al principio de igualdad ${ }^{65}$.

En cualquier caso, no se desatiende la utilidad. Las prohibiciones se justifican solamente porque es socialmente útil (dentro de ciertos límites) que no se realicen cier-

58 VON HiRSCH (n. 18), 60 y ss.; FLETCHER (n. 32), 813.

59 HART (n. 18), 9, cursivas del original. La misma distinción, aunque no con las mismas consecuencis, M. BAURMAnN, 1990, «Strafe im Rechtsstaat», BAURMAnN/KLIEMT (comp.), Die moderne Gesellschaft im Rechtsstaat, Freiburg-München: Alber, 109, 144 ss.

${ }^{60} \operatorname{HART}($ n. 18), 11, la cursivas no pertenecen al original.

Sin embargo, sí hay diferencias prácticas entre la postura retribucionista y la teoría distributiva que se sigue aquí. La primera (1) es que el retribucionista siempre deberá procurar que cada pena se acerque al ideal de merecimiento absoluto, más alla de que esto sea muy difícil de determinar. En cambio, el distribucionismo admite penas por debajo de la culpabilidad, siempre que esa variación se distribuya para todos por igual. En este sentido, de acuerdo al criterio distributivo, los sistemas penales pueden ir perdiendo paulatinamente su rigor sin que ello sea óbice a respetar los principios mencionados. Un retribucionista coherente no podría admitir esto. La segunda diferencia (2), es que el distributivista que defiende una teoría preventiva de la pena (en realidad, sólo así tiene sentido defender esta postura) aún debe hacer cálculos de costos y beneficios. Dichos cálculos no se realizarán autor por autor y pena por pena, pero sí en general. De tal manera que es lógica y empíricamente posible deslegitimar todo el sistema de castigo penal, si éste no da un resultado positivo en su totalidad. Puesto que al retribucionista esto no le importa (a lo sumo, como para KöHLER, STRAFRECHT, AlLGEMEINER TEIL, Berlin: Springer (entre otras), 1997, 51, será un efecto concomitante bienvenido), el resultado de esas operaciones no lo condiciona en absoluto.

${ }^{61} C f r$. (n. 18) y en obras posteriores.

62 Von Hirsch (n. 18), 60.

${ }^{63}$ Hörnle (n. 22), 23, también Clark (n.41), 132; VON HirSCH (n. 18), 59 s. y 61 y ss.

${ }^{64}$ HÖRnle (n. 6), 108 y ss.; VON HiRsch (n. 18), 66, 69 y ss.; HÖRNLE/VON HiRsCH, 1995, Positivegeneralprävention und Tadel, GA, 262 y ss.

${ }^{65}$ El fundamento de VON HIRSCH y HÖRNLE ( $c f r$. citas de la nota anterior) parece por momentos un tanto confuso, pues ambos recalcan que el fundamento de la pena en general no tiene repercusión sobre su medida en el caso concreto, pero a su vez reconocen que comunicar el reproche con el monto de la pena es, en sí, un fin de ésta. 
tas conductas (cualquiera sea la finalidad de la pena que se considere adecuada o legítima) y se castiga también sólo porque es útil. Es decir, ni se prohíbe ni se castiga para hacer justicia metafísica, pero si se castiga, entonces no se puede hacer de cualquier modo $^{66}$, se debe hacer distribuyendo el castigo con equidad. Este principio de distribución del castigo no se satisface cuando un autor es sancionado con menos dureza que otro, no por haber hecho algo diferente, sino porque no es necesario de acuerdo a ciertos fines de la pena sancionarlo con igual intensidad ${ }^{67}$. El objetivo principal, entonces, de una comprensión como ésta es refutar la teoría de la culpabilidad como límite máximo, que sostiene que el único criterio de carácter no utilitarista que interviene en la determinación de la pena es la no superación del marco delimitado por la culpabilidad. Por el contrario, la pena será moralmente aceptable sólo si se puede afirmar que se ha respetado a los sujetos que la padecen tratándolos a todos por igual.

\subsection{Justificación de la dogmática del hecho punible como criterio para establecer la igualdad}

Ahora bien, asumido que eso es correcto, ¿de acuerdo a qué criterio se puede afirmar que se está respetando la igualdad en la distribución de la pena? Es decir, ¿cuáles son los factores relevantes para hacer diferencias de pena entre dos sujetos y cuáles no? ¿Cuándo se puede decir que un hecho reviste más gravedad en el Derecho penal? Esta pregunta es obviamente fundamental. Hasta acá nos hemos manejado intuitivamente con la idea de merecimiento, pero es necesario aún especificar cuándo algo es merecido y puede ser incluido legítimamente entre los elementos a distribuir y cuándo debe ser excluido. La respuesta a esta pregunta la brinda la dogmática ${ }^{68,69}$.

Existen cuatro elementos en común que caracterizan a la dogmática i. e. a la teoría del delito de tradición alemana: acción, tipicidad, antijuridicidad (que es lo que nos permite hablar de injusto o ilícito penal) y culpabilidad ${ }^{70}$. Las opiniones que discrepan con esta clasificación son tan aisladas que pueden ser desestimadas a la hora de hacer un trabajo como el que estamos discutiendo. Esto nos permite hablar de la dogmática y de las categorías del delito sin necesidad de hacer aquí más distinciones.

En la ciencia del Derecho penal, la dogmática del hecho punible cumple explícitamente dos funciones fundamentales: 1. determinar en qué casos está justificado castigar y 2. encontrar soluciones uniformes a problemas uniformes ${ }^{71}$, lo que a la postre no es más que lo mismo. La dogmática es el método científico por excelencia, por lo me-

${ }^{66}$ FLETCHER (n. 32), 809 y ss.

${ }^{67}$ Fletcher (n. 32), 813; FerRajoli (n. 55), 406.

${ }_{68}$ En contra HöRnLE (n. 6), 134, con el argumento de que la justicia es un argumento vacuo, imposible de llenar con sentido. Al respecto, lo que sigue.

69 En este texto se utilizarán como sinónimos las siguientes expresiones: dogmática, dogmática del hecho punible y teoría del delito. Esto es usual entre los penalistas, debido al gran desarrollo que ha recibido la teoría del delito, cuya «dogmática» es el trabajo de los científicos del Derecho por excelencia.

${ }^{70}$ La presentación y desarrollo de estas categorías puede verse en cualquier manual de Derecho penal que siga esa tradición. Una breve explicación al respecto infra 4.2.2.

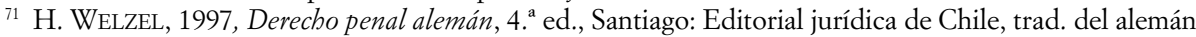
de Bustos RAmíreZ/PÉREZ, 1; SILVA SÁNCHEZ, 1991, Aproximación al derecho penal contemporáneo, Barcelona: Bosch, 47 y 50. 
nos en los países que siguen la tradición alemana, utilizado en el ámbito penal para el análisis del Derecho. A pesar de la enorme variedad de teorías del delito y de puntos de vista sobre otras discusiones dogmáticas relevantes (casi) todas ellas pretenden hacer una cosa y por ello es que compiten: determinar cuándo el castigo penal debe ser considerado político criminalmente aceptable. En este sentido, la dogmática penal establece lo que debe ser sin ningún tipo de ambigüedad ${ }^{72}$. Asimismo, la dogmática cumple la importantísima función de otorgar previsibilidad y uniformidad a las decisiones judiciales. Esto se logra a raíz de su fuerte carácter sistemático, que tiene como fondo indubitable el respeto a la igualdad ${ }^{73}$, en la medida en que procura distinguir con precisión distintos tipos de problemas para darle a cada uno el tratamiento que corresponde, sin caer en la casuística.

Si esta argumentación se traslada a la medición de la pena, con las precisiones que se harán más adelante, lo que se estará haciendo es buscar legitimidad para la justificación de cada segmento de pena. Las variaciones de pena sólo podrán estar justificadas en la medida en que, luego de un análisis minucioso, se pueda predicar de ellas que dan cuenta de ciertas estructuras que legitiman el castigo en general. De esta forma, castigos de diferente intensidad sólo encontrarán razón de ser en que son el reflejo de hechos que merecen un castigo diferente porque reflejan distintos grados de culpabilidad por el hecho, entendido el hecho como un ilícito penal. Si el único criterio de legitimación del castigo lo brinda la dogmática, «no pueden existir factores relevantes para la individualización de la pena... que carezcan de un soporte categorial en la teoría del delito» ${ }^{74}$, con las precisiones que se formularán más adelante.

A pesar del extraordinario desarrollo de la dogmática, su labor se ha centrado casi exclusivamente en determinar la legitimidad del «sí» de la pena, dejando de lado el problema en torno al «cuánto». Aunque esto siempre estuvo, de todas formas, latente. Desde el momento en que el riesgo para el bien jurídico de una conducta es graduable, desde que las causas de exculpación implican, por lo menos también, una disminución del injusto, desde que el dolo directo se ha considerado más grave que el dolo eventual y que la culpabilidad disminuida atenúa la pena, las repercusiones de la dogmática para la medida de la pena ha estado siempre allí. Sin embargo, no ha sido sino hasta estas últimas décadas que la vinculación entre ambas esferas ha sido comprendida en su totalidad. Aquella desatención pasada pudo deberse, como dice SCHÜNEMANN, a un «tradicional desinterés» de los dogmáticos sobre el tema ${ }^{75}$ o, quizás, como dice SiLVA SÁNCHEZ, a una esforzada «autorestricción» de ésta, debido a que se ha relacionado siempre de manera directa determinación y fines de la pena ${ }^{76}$. En cualquier caso, el problema de la

72 Con esto se hace referencia, entre otras cosas, a la discusión que mencionan J. A. DíEZ y U. MoulinES, 1999, en Fundamentos de la filosofía de la ciencias, 2. "a ed., Barcelona: Ariel, 19 y ss, 21 y ss. en cuanto afirman que la ciencia del Derecho es descriptiva, en la medida que da cuenta de normas existentes, y prescriptiva en la medida en que de esa «descripción» surge una «prescripción», pero siempre derivada de aquélla y no autónoma. Pues bien, la dogmática no hace esto. La dogmática prescribe en el sentido fuerte de la expresión, siempre que, como se dijo, la indeterminación legal o lingüística lo permitan.

73 B. SCHÜNEMANN, «Die Funktion der Abgrenzung von Unrecht und Schuld», en SCHÜNEMANN/FIGUEIREDO DiAS (comps.) Bausteine des europäischen Strafrechts, Coimbra Symposium para RoxiN, Múünchen-Coimbra: Heymanns, 149, 154.

74 SiLVA SÁNCHEZ (n. 19), 9

75 Prólogo a HÖRnLE (n. 22), 17.

76 Silva SÁnCHez (n. 19), 3. 
distribución justa del castigo se encontraba soslayado en un punto de trascendencia indiscutible para el individuo a penar, el de la determinación de la pena concreta.

De lo que se dijo se sigue lo siguiente: (i). El juez no «debe perseguir por sí mismo efectos sobre la colectividad $\gg^{77} \mathrm{y}$ tampoco de prevención especial ${ }^{78}$. Los fines de la pena pasan a un segundo plano. (ii). No existe diferencia alguna entre culpabilidad fundamentadora y culpabilidad de la determinación de la pena ${ }^{79}$, que con tanta facilidad dejaba las puertas abiertas a considerar a «cualquier factor como relevante para fijar la pena» ${ }^{80}$. (iii). No existe un conflicto entre culpabilidad y prevención en la determinación judicial de la pena. Éste será sólo un reflejo de la tensión general entre utilidad dely límites al castigo.

Ahora bien, para que todo esto tenga sentido, los marcos penales previstos para los tipos de la parte especial deben ser entendidos de la siguiente manera.

\subsection{El marco penal como escala de gravedad continua. La determinación de la pena como un reflejo de la teoría del delito.}

\subsubsection{Generalidades}

El análisis debe empezar, entonces, considerando que los marcos penales contienen escalas de gravedad continua. Éstos demarcan la gravedad mínima y máxima del delito y la gravedad de la pena en el caso concreto deberá determinarse en relación a ellos ${ }^{81}$.

Para aplicar aquí las construcciones dogmáticas se debe partir de dos presupuestos: 1 . de que ningún factor cuenta para la determinación de la pena si no tiene relación con el injusto y la culpabilidad; 2. de que ambos factores son graduables. En un trabajo muy reciente, SILVA SÁNCHEZ, siguiendo la línea trazada por HörNLE, ha hecho un planteo similar utilizando expresiones muy gráficas. En palabras de SiLVA, la determinación de la pena se manifiesta «como la dimensión cuantitativa (o de grado) de un sistema de la teoría del delito», en donde injusto, culpabilidad [...] «constituyen magnitudes materiales graduables» ${ }^{82}$. En este sentido, «el marco penal abstracto puede verse como la unión de un conjunto de conminaciones penales más detalladas (submarcos) que asignarían medidas diversas de pena a las distintas subclases de realización (subtipos), más o menos graves, del injusto culpable y punible expresado» ${ }^{83}$. De esta forma,

77 García Aran (n. 22), 512.

${ }^{78}$ Esta última deberá ser entendida sólo como una oferta para el condenado una vez que la pena haya sido fijada de acuerdo a otros parámetros. HASSEMER (n. 15), 250; SILVA (n. 71), 37; LESCH (n. 9), 591 y ss.

79 Similar B. SCHÜNEMANN, 1989, «Die Entwicklung der Schuldlehre in der Bundesrepublik Deutschland», en Strafrecht und Kriminalpolitik in Japan und Deutschland, HIRSCH/WEIGEND (comps.), Berlin, 147, 160.

${ }^{80}$ ZIFFER (n. 2), 92.

${ }^{81}$ ZIFFER (n. 2), 41.

82 Aquí se excluye deliberadamente la punibilidad, que fuera incluida por SILVA, como categoría graduable. Esto se debe a que la punibilidad, es una categoría extremadamente heterogénea, donde se puede incluir, sin necesidad de demasiada fundamentación, como si se tratara de un «cajón de sastre» cualquier elemento que no «encaje» en alguno de los otros dos componentes relevantes para el delito. Cfr. el propio SiLVA (n. 19), 9.

83 SiLVA SÁNCHEZ (n. 19), 5 y 8. 
la escala penal no cumple ya simplemente la función de fijar límites al juez, sino que constituye una escala continua en la que el juez debe encontrar la pena correcta ${ }^{84}$.

Para determinar la pena de este modo y para no incluir elementos ad-boc es necesario contar con cierta claridad acerca de los factores que cuentan para la teoría del delito, para posibilitar así un control estricto de los elementos de que se vale el juez para determinar la pena. Se podrán tener diferentes teorías del ilícito y culpabilidad, pero éstas siempre deberán ser expresadas, de modo tal que puedan ser controladas. Es en este lugar donde tienen relevancia práctica cuestiones como la importancia de la intención (como característica del dolo directo) en el delito, sobre cuánto cuenta el resultado y por qué, si la conducta de la víctima puede ser considerada un atenuante para la responsabilidad del autor, etc. En este sentido, la teoría de la determinación de la pena se transforma en «un ámbito idóneo... para derivar importantes consecuencias de la postura que se mantenga respecto a problemas como el contenido y graduabilidad del injusto y la culpabilidad...» ${ }^{85}$.

\subsubsection{La función del injusto y la culpabilidad en la determinación de la pena}

Decisivo, entonces, serán el grado de injusto y el grado de culpabilidad, de acuerdo a la graduación de cada uno de sus elementos ${ }^{86}$. A grandes rasgos, el injusto o ilícito penal, que hace referencia a la dañosidad social de la acción, se divide en dos partes (1) la objetiva y (2) la subjetiva.

(1) La parte objetiva se caracteriza, a su vez, por dos elementos. El primero es la imputación objetiva de la conducta. Ésta consta de la creación de un riesgo no permitido para el bien jurídico y de la realización de ese riesgo en el resultado. El primer factor relevante para la determinación de la pena será el grado de riesgo que la conducta del autor implica para el bien jurídico ${ }^{87}$. Por riesgo debe entenderse, grosso modo, la potencialidad general de la conducta de producir un daño. Así, usar un arma larga implicará, ceteris paribus, un riesgo mayor que usar un arma corta, porque con aquélla aumenta la probabilidad de darle al blanco. Luego, habrá que evaluar cuánta incidencia tuvo ese riesgo en el resultado finalmente producido. Siguiendo con el ejemplo anterior, supongamos que el arma disparaba un sedante, pero debido a que el autor había injerido una sustancia rarísima que combinada con aquél agrava el estado de la víctima, finalmente quedó sedado por mucho más tiempo del calculado. Ese resultado, no imputable al riesgo de la conducta, no puede tener relevancia en la medición de la pena. El segundo elemento objetivo es el resultado en sí mismo ${ }^{88}$, cuya ausencia total o parcial puede repercutir a favor el imputado. Si el sujeto generó un riesgo elevado de lesión, en el caso en cuestión, de sedar con un arma larga, pero luego, por azar, el resultado se produce con menos intensidad, supongamos, porque el sujeto había tomado

84 STRENG (n. 34), 1461.

85 García Aran (n. 22), 511 y ss.; similar también E. Demetrio CresPo, 1997, «Análisis de los criterios de la individualización judicial de la pena en el nuevo código penal español de 1995», ADPCP, 323, 333. De la misma manera HÖRNLE (n. 5), 145 ss.

${ }^{86}$ Cfr. SÁNCHEZ (n. 19), 11 y ss.

87 También Ashworth (n. 56), 88.

88 JESCHECK (n. 31), 888. 
otra sustancia rarísima que atenuaba los efectos del sedante, esa no producción del resultado puede jugar a favor del autor. Que deba ser así es más que discutible, pero sobre eso no se puede profundizar aquí ${ }^{89}$.

Un camino similar al aquí propuesto fue insinuado por BAIGÚN (1971), aunque no con una visión completa al respecto. BAIGÚN, al tratar acerca de la «naturaleza de las circunstancias agravantes», afirmaba que respecto de ese tema no había habido mayores innovaciones hasta ese momento, porque éstas figuraban demasiado vinculadas a la individualización de la pena ${ }^{90}$, cuando, en realidad, su «esencia» debía «asimilarse a la del tipo». Y esto es efectivamente correcto, las circunstancias agravantes constituyen partes del tipo penal, pero no se deben diferenciar de las circunstancias que sirven para la determinación de la pena, justamente porque éstas también forman parte del tipo penal. Esta distinción se explica en BAIGÚN porque si bien para él muchos de los factores mencionados en los arts. 40 y 41 tenían la misma estructura que las agravantes, creía también que había factores que no se podían explicar de ese modo y que, en realidad, constituían «auténticos índices de punición» ${ }^{91}$.

(2) La parte subjetiva del injusto consta de dos elementos principales, a saber, el dolo y la imprudencia. En el dolo, a su vez, se considera conocimiento que haya tenido el sujeto del riesgo generado por su conducta, y la intención. Subjetivamente, sólo se le pueden imputar al autor el riesgo generado y el daño causado en la medida en que eran conocidos o cognoscibles por él. Así, por ej., si el autor genera un riesgo del bien jurídico de 8 en la escala del 1 al 10, pero sólo tiene un conocimiento de 6 , en la medida en que este desconocimiento parcial no le sea imputable, no podrá contar en su contra y, por ende, se lo responsabilizará sólo por el riesgo 6. Es decir, cabe aquí aplicar la teoría del error con todas sus consecuencias en relación al subtipo que se haya configurado objetivamente. El otro factor subjetivo es la intención. Su inclusión, a diferencia del conocimiento, que es aceptada en general, hoy se encuentra en crisis, pero esto tampoco puede ser analizado en este lugar ${ }^{92}$. Si es que la intención juega algún rol relevante para la teoría del delito, entonces su relevancia se verá reflejada en la medición de la pena ${ }^{93}$.

Las causas de justificación excluyen la ilicitud del hecho. Si el hecho está justificado no habrá lugar a la determinación de la pena. De todas formas, aun cuando no está justificado, su proximidad con una causa de justificación sí es relevante para la medida de la ilicitud. Éste es el fundamento de la pena disminuida cuando hay exceso en una causa de justificación (art. $35 \mathrm{CP}$ argentino, 21.1 del CP español en función de 20.4, 20.5 y 20.7), pero su fundamentación se puede extender a situaciones análogas. Por ejemplo, si A para salvar un bien de su propiedad de escasa importancia destruye un bien de mayor valor de $\mathrm{B}$ y, por ende, causa un daño mayor para evitar uno menor, el hecho no está justificado. De todas formas, que ese daño no haya sido infundado, sino que se haya acercado a lo que constituye un estado de necesi-

${ }^{89}$ Fundamental al respecto M. A. SANCINETTI, 1991, Teoría del delito y disvalor de acción, Buenos Aires: Hammurabi, 1991, pássim; Ashwort (n. 56), 88 y ss.

90 Baigún (n. 15), 26.

91 Baigún (n. 15), 46 y ss. También 87.5.

92 Cfr., por todos, sobre la discusión, RoXin (n. 10), 12/1 y ss.; SANCINETTI (n. 89), 145 y ss.

93 En contra JESCHECK (n. 31), 887 
dad, debe influir en la medida del injusto o por lo menos de culpabilidad ${ }^{94} \mathrm{y}$, por ende, debe considerarse relevante para la medición de la pena. Si se entiende el marco penal como un conjunto de submarcos dividido en diferentes subtipos penales, lo que de aquí se sigue es que algunos tipos estaban justificados y otros no y, por ello, sólo se responde por lo que resta de injusto, por aquella parte o aquellos subtipos no justificados.

Otros elementos cuya relevancia para el injusto no se discute (aunque sí su ubicación sistemática), deberán también ser mensurados aquí. El consentimiento es considerado normalmente una causa de justificación, aunque hay una nueva tendencia a considerarla una circunstancia que elimina ya el tipo ${ }^{95}$. En cualquier caso, la configuración de una situación similar a la del consentimiento, o la del consentimiento mismo, aunque éste no sea decisivo para la existencia del injusto, debe contar igualmente para la medición de la pena. HiLlenKAmP, en la segunda parte de su obra, «Hecho doloso y conducta de la víctima» $\left(1981^{\% 6}\right)$, trata este tema y situaciones similares, dando como fundamento de la atenuación de la pena la proximidad de ciertas situaciones a lo que se considera normalmente una causa de justificación ${ }^{97}$. Un ejemplo en este sentido es el caso del «consentimiento» dado por un menor para tener relaciones sexuales. Si bien por su condición su consentimiento carece de relevancia para el «sí» de la pena, esta circunstancia debe ser considerada, porque se acerca a la del consentimiento, lo cual ubica a la conducta del autor en un nivel de menor merecimiento de pena, de aquel que con engaño o violencia somete a un menor a los mismos hechos ${ }^{98}$.

La culpabilidad en sentido estricto es el segundo gran factor que cuenta para la existencia de un delito. La esencia de la culpabilidad en materia penal es, en palabras de Roxin, «un tema eterno del Derecho penal» que está expuesto a dudas que nunca serán despejadas ${ }^{99}$. Pero este problema puede ser dejado de lado a los fines que aquí interesan. Lo esencial, ahora, es saber que la culpabilidad es lo que permite atribuirle al autor el hecho que ya es considerado, en mayor o menor grado, socialmente dañoso. Cualquier concepto de culpabilidad parte de la idea de responsabilidad individual y pretende determinar si, de acuerdo a las características del autor o su situación concreta, el hecho le puede ser reprochado. Dejando de lado este lugar común, aún pueden distinguirse dos grandes formas de concebir la culpabilidad. Ésta puede ser entendida simplemente como un elemento que posibilita la imputación del ilícito (en donde hay una identidad en entre el presupuesto básico de atribución de responsabilidad y reproche) o también como un elemento de la teoría del delito que, además de dar cuenta de

${ }^{94} \mathrm{Si}$ esto debe repercutir en el injusto o en la culpabilidad y en qué medida es algo que depende, en gran parte, del fundamento de la justificación de la conducta en estado de necesidad. Si su fundamento es puramente utilitarista, entonces, al haber un daño menor cuando el hecho tiene una justificación parcial, esto implica una disminución de la dañosidad social del hecho. Si, en cambio, su fundamento radica en un deber de solidaridad por parte del tercero que ve, por ejemplo, un detrimento de su patrimonio, la fundamentación de la atenuación se deberá buscar en la culpabilidad o no encontrará justificación alguna. Pues el deber de solidaridad sólo nace cuando el riesgo para el bien jurídico del autor es realmente intenso. Cfr., al respecto, HöRNLE (n. 6), 294 y ss.

${ }^{95}$ Cfr., al respecto, Roxin (n. 10), 13/1 y ss. en especial 12 y ss.

96 T. Hillenkamp, 1981, Vorsatztat und Opferverhalten, Göttingen: Otto Schwartz \& Co, 211 y ss.

97 En especial las páginas 242 y ss., 269 y ss.

${ }_{98}$ HillenKamp (n. 96), 243 y ss.

99 Roxin (n. 34), 147. 
la estructura principal, tiene un contenido material propio (sólo una parte de la culpabilidad está relacionada con la atribución del hecho cometido, mientras otra parte tiene una explicación diferente) ${ }^{100}$.

Esta segunda comprensión de la culpabilidad es denominada de actitud interna o de ánimo (Gesinnungsschuld). De acuerdo a ella, al sujeto se le reprocha, además de su ilícito, su actitud interna presente en el hecho. De esta forma, dado que se puede reprochar la actitud del sujeto que no se refleja en la modalidad del hecho concreto (de otra forma será un elemento del injusto), la culpabilidad puede fundamentar espacios o montos de pena de manera independiente a aquél. Ella misma es un elemento que se puede sumar al injusto como elemento determinante de la pena. Esta concepción, sin embargo, se encuentra en crisis y por buenas razones ${ }^{101}$. No es éste el lugar para explayarse al respecto, baste con decir que tiene serios inconvenientes para encontrar un lugar en un Derecho penal liberal, por su ostensible vinculación con un Derecho penal de autor (cfr. también infra 5).

Por el contrario, si por culpabilidad se entiende sólo un proceso de imputación, únicamente interesa saber si el sujeto que actuó en contra de la norma la conocía o podía conocerla y si tenía normalidad motivacional. En la culpabilidad se analiza, entonces, sólo la posibilidad de poder atribuir el injusto al sujeto, es decir, hacerlo responsable por lo que ha hecho ${ }^{102}$. Entendida de esta forma, la culpabilidad no puede fundamentar montos de pena de manera separada del injusto. O bien se atribuirá el ilícito penal de manera completa o bien se lo atribuirá de manera parcial (debido a dificultades que haya presentado para poder seguir la norma o conocerla) o bien no se le atribuirá en absoluto, pero la culpabilidad no cumplirá ninguna función fundamentadora que no se encuentre en relación con el ilícito cometido. En palabras de HÖRNLE: «Las graduaciones de la medida de la culpabilidad sólo son posibles en una dirección: en caso de concurrencia de causas de disminución de la culpabilidad, pero no en forma de incremento de la medida de al culpabilidad» ${ }^{103}$. Así, no se habla ya de «máxima culpabilidad», sino de «culpabilidad completa» ${ }^{104}$.

\subsubsection{Posibles dificultades prácticas de una postura dogmática de la determinación de la pena}

Esta propuesta es criticada por ser poco realista ${ }^{105}$. Existen infinitas graduaciones posibles de los factores relevantes para el injusto y la culpabilidad y demasiadas combinaciones imaginables entre ellos. Esto hace muy difícil determinar cuál medida de pena se corresponde con la conducta evaluada. Además, la escala penal es un continuo $\mathrm{y}$ ante dos fundamentaciones bien estructuradas de la responsabilidad penal, que lle-

${ }^{100}$ Fundamental al respecto HÖRNLE (n. 22), 37 y ss.; también en 2003, «Kriterien Kriterien für die Herstellugn von Tatproportionalität», en FrISCH/vON HiRSCH/AlBRECHT (comp.), Tatproportionalität, Heidelberg: C. F. Müller, 99, 123 y ss.

101 Cfr. HÖRNLE (n. 22), 39 y ss.

102 SCHÜnEMANN (n. 79), 160.

103 HÖRnle (n. 22), 54 y ss.

104 STRENG (n. 34), 1423.

105 STRENG (n. 34), 1461 
guen a montos de penas próximos pero diferentes, será difícil, si no imposible, determinar cuál de las dos penas es la correcta o la que más plausibilidad tiene.

Esto es cierto, pero, obviamente, no es un problema exclusivo de esta teoría ni lo que aquí se quiere desvirtuar. Esta vaguedad la comparte cualquiera de las construcciones antes señaladas. Sólo existen márgenes de plausibilidad de penas correctas, lo que fue demostrado por la teoría del espacio de juego y que no es poco. Pero lo positivo de este punto de vista no es que elimine esa vaguedad intrínseca al problema de la proporcionalidad, sino que deja bien claro qué es lo que el juez puede considerar relevante para la determinación de la pena y qué no, no admitiendo argumentos que no tengan que ver exclusivamente con el ilícito y la culpabilidad. De esta forma, se garantiza una distribución del castigo de acuerdo a principios de equidad «en la medida de lo posible» ${ }^{106}$ y que se tienda a argumentar de esa manera.

Los argumentos que no tienen un soporte categorial en la teoría del delito, como lo son las necesidades de retribución o de prevención general o especial, se transforman en elementos ilegítimos para la medición de la pena y tienen un valor similar a otros factores que ya se encontraban excluidos incluso en las teorías criticadas precedentemente. Así, por ejemplo, para una teoría de base exclusivamente utilitarista la nacionalidad del sujeto no puede ser relevante de por sí para medir la pena. Aun así, aquí tampoco existen posibilidades de control estricto de que el juez no se haya dejado llevar por su xenofobia. Eso supondría la determinabilidad exacta de las necesidades preventivas, lo que dista de ser posible. Sólo sabemos que él no puede usar ese argumento válidamente y que, ante circunstancias iguales, es decir, ante las mismas necesidades preventivas (en este caso más difíciles de controlar que en un sistema de base exclusivamente dogmática), debe resolver de la misma manera aunque el acusado no sea un extranjero ${ }^{107}$.

\subsubsection{Otras ventajas en relación a otras teorías de determinación de la pena}

(a) Prevención general y prevención especial como criterios exclusivos de determinación de la pena tienen dos deficiencias en común. (1) Admiten que se sancione al sujeto por encima de la culpabilidad. Esta posible crítica es consabida, pues en la medida en que la pena se determina en base a necesidades empíricas concretas, no hay ninguna razón lógica para suponer que habrá alguna coincidencia entre culpabilidad y prevención, que pase de ser casual. Pero, además (2) ambas violan la autonomía de las personas en el siguiente sentido: no se puede hacer un cálculo de las consecuencias del acto. Las necesidades de pena se determinarán siempre ex post y, por ende, no pueden ser calculadas por el autor. Es claro que es poco realista pensar que quien está por cometer un delito hará un cálculo exacto de las consecuencias jurídicas de su acto. De todas formas, a éste le debe ser posible hacerlo. Si bien el autor tiene prohibido cometer el hecho, en el caso que se decida por ello no sólo debe poder conocer que será penado, sino también con qué intensidad. Esto, en general, debería considerarse parte del principio de legalidad cuando se habla de las escalas penales. Con nuestra postura eso

\footnotetext{
${ }^{106}$ HÖRNLE (n. 6), 70 y 147 ss.

107 Frisch (n. 52), dice que sólo quedan para estos casos «determinadas reglas de procedimiento».
} 
se puede profundizar mucho más, posibilitándole al autor hacer un cálculo más preciso de las consecuencias de sus actos.

Quizás valga la pena también hacer la siguiente aclaración. La autonomía que resulta violada en este caso difiere de la que se viola exclusivamente con la determinación de la pena basada exclusivamente en criterios de prevención especial. Una pena determinada sólo de esa manera viola la autonomía de los individuos en el sentido de que estimula ciertos modos de vida - independientes del hecho cometido- en detrimento de otros. A lo que se hace referencia ahora es a la posibilidad de elegir qué sanción se quiere padecer con el acto a realizar. Quien sale a robar debe saber en qué caso recibirá más pena, si usa un palo o un cuchillo, para elegir qué riesgo quiere correr. La prevención especial como criterio exclusivo para fijar la pena viola ambas clases de autonomía.

(b) En relación a la teoría de la «culpabilidad como límite máximo», que pretende combinar culpabilidad y prevención, presenta la ventaja de que impide la manipulación expresa de argumentos. En efecto, para que la culpabilidad pueda funcionar realmente como límite máximo, ese límite se debe poder precisar. Pero resulta que esto es tremendamente dificultoso, como lo demuestran las discusiones acerca de la relevancia del resultado para el concepto de delito, en donde afirmar que el resultado aumenta la necesidad de pena y, con ello, permite superar ilegítimamente el límite de la culpabilidad y afirmar lo contrario, esto es, que la ausencia de resultado es la que disminuye la necesidad de pena de un hecho ya adecuado a la culpabilidad, es igualmente plausible. Los contrincantes en esta discusión no tienen ningún punto en que pararse para demostrar quién lleva razón. Todo dependerá, al final, de qué se haya dicho primero. Con ello se pueden introducir encubiertamente justificaciones de montos de pena en base a factores no legítimos. En la medida en que para la propuesta aquí defendida esos argumentos no cuentan en absoluto, no hay posibilidad de manipulación expresa alguna.

\section{EL PROBLEMA DE LOS MOTIVOS PARA DELINQUIR}

Como ejemplo de lo fructífera que puede ser una teoría como la aquí defendida, vamos a analizar el problema de los motivos para delinquir. Su valoración representa posiblemente uno de los obstáculos más fuertes a una reconstrucción dogmática liberal de todos los elementos enumerados por el legislador como relevantes para la medición de la pena, pues resulta extremadamente dificultoso encontrar su relación con un Derecho penal de acto donde todas las reglas relevantes para la determinación de la pena deben considerarse normas de conducta.

Es claro que explican la génesis del delito ${ }^{108}$, pero de ello no se sigue nada. También explica la génesis del delito cometerlo por motivos altruistas y estos motivos no constituyen una agravante. Los motivos abyectos sí configuran una génesis moralmente deplorable, seguramente conforme a la moral positiva y crítica ${ }^{109}$. Pero todos sabemos que no es tarea del Derecho liberal mejorar la situación moral de sus ciudadanos.

\footnotetext{
${ }^{108}$ H. MARCHIORI, 1983, Las circunstancias para la individualización de la pena, Córdoba: Lerner, 41.

109 BGHSt (sentencias del Tribunal Supremo Alemán en asuntos penales), 3, 132
} 
Constituye un lugar común, no obstante, afirmar que si bien la motivación inmoral por sí sola no puede ser objeto de una prohibición, sí puede ser valorada cuando se haya cometido un ilícito cuya prohibición se encuentre justificada de otra manera ${ }^{110}$. Sin embargo, si se sostiene, como aquí se hace, que para la medición de la pena sólo pueden contar los elementos relevantes para la teoría del delito, con esta constatación no se gana nada. En palabras técnicas, el subtipo por el cual se agrava un delito por la inmoralidad del motivo del agente sería un subtipo iliberal y, por ende, inaceptable.

Es común, asimismo, que se confundan los niveles de análisis al vincular los motivos directamente con la dificultad de ganarse el sustento. DEMETRIO CRESPO afirma que la motivación indica la posibilidad de poder motivarse de otra manera del agente ${ }^{111}$. En el mismo sentido, ZAFFARONI señala: «La motivación es la base del reproche de culpabilidad por el acto: el motivo funda un mayor o menor reproche en razón directa con [la intensidad de su aberración y] el grado de escogimiento o ámbito de autodeterminación constelacional concreta» ${ }^{112}$, pues «la esencia de la misma es, precisamente, haber podido motivarse de otra manera ${ }^{113}$.

Pero, en realidad, se trata de dos cuestiones independientes. La dificultad para ganarse tiene un doble fundamento reductor. Por un lado, su proximidad al estado de necesidad implica una reducción del injusto y, por el otro, puesto que significará una reducción del ámbito de libertad del sujeto, constituye una reducción de la culpabilidad ${ }^{114}$. Por el contrario, motivos socialmente valiosos no implican, necesariamente, un menor ámbito de libertad del sujeto. De la misma manera, motivos abyectos no implican, forzosamente, más autonomía para decidir. Obrar por un motivo altruista, patriótico o para defender el honor no implica más apremio, aunque no lo excluya. Obrar por odio racial o religioso o por codicia no implica más autonomía e incluso es posible que en la mayoría de los casos suceda justamente lo contrario.

Otra justificación posible de los motivos está relacionada con el injusto. Con un concepto de injusto basado en el reestablecimiento del valor contenido en la norma jurídica los motivos pueden ser relevantes. Si lo que se quiere proteger con la prohibición de, por ejemplo, matar, es el valor vida y no la vida de un sujeto concreto, el obrar por codicia legitima el uso de una pena de mayor intensidad. El valor vida resulta más cuestionado cuando se obra por motivos tan viles como la codicia o el placer y, en consecuencia, sólo una pena más fuerte puede volver las cosas a su estado anterior ${ }^{115}$. Pero si

${ }^{110}$ CLARK (n. 41), 134 y ss.; SANCINETTI (n. 89), 342 y ss.

111 Demetrio Crespo (n. 85), 336; similar C. LuRATI, 2004, «La intervención de un menor y el uso de armas como agravantes en la parte general», en E. A. DonnA (cord.) Reformas penales, Santa Fe: Rubinzal-Culzoni, 43, 51

112 ZaFfaroni (n. 12), 1035 y 1051. Aquí ZaFFaroni ha dicho dos cosas que deben ser analizadas independientemente. Una, que hace referencia a la intensidad de la aberración del motivo y otra que se vincula con la «libertad» para actuar. Aquí se hace referencia sólo a lo segundo. De allí los corchetes que señalan lo que no debe leerse en esta afirmación

113 ZAFFARONI (n. 12), 1052 llega incluso a relacionar esto con el problema del error, pero esta vinculación un tanto sorprendente no puede ser analizada aquí.

${ }^{114}$ Cfr. J. De la Rúa, 1997, Código Penal Argentino, Depalma, 709; O. Breglia Arias y O. R. Gauna, 2003, Código Penal y leyes complementarias, 6. ${ }^{a}$ ed., Buenos Aires: Astrea, 362. En el mismo sentido Hart (n. 18), 16; STRENG (n. 34), 1435; SCHAFFSTEIN (n. 34), 110.

115 SCHÜNEMANN (n. 73), 182; B. HAFFKE, 1978, «Strafrechtsdogmatik und Tiefenpsychologie», GA, 33, 48; JAKOBS, 1969, «Niedrige Beweggründe beim Mord und die besonderen persönliche Merkmale in $₫ 50$ Abs. 2 und $3 \mathrm{StGB} \gg$, NJW, Heft 12, 489, 490. 
lo que se quiere lograr con la pena es proteger un bien jurídico tangible, la voluntad de vivir de un sujeto concreto, y no el valor vida como una entidad abstracta, el motivo vil no parece agregar nada. La conducta no es objetivamente más riesgosa y el resultado tampoco es más grave. El conocimiento de la realización del estado de cosas que se quiere evitar no tiene por qué ser mayor o menor en estos casos. Tampoco aumenta la intención. No hay más intención de matar, por ej., que al hacerlo porque el otro sea simpatizante o hincha de otro equipo que hacerlo para enarbolar la bandera de la libertad. La intención no cambia.

SILVA SÁnCHEZ afirma que la relevancia de los motivos para el Derecho penal está en su fuerza comunicante y admite que esto se diferencia completamente de la concepción de un injusto dirigido a la protección de bienes jurídicos. Pero afirma que ésta es la única forma de dar cuenta de los motivos ${ }^{116}$, pues, como se dijo, en principio, no tienen incidencia ni en la culpabilidad ni el injusto entendido como se ha descrito en este trabajo. Pero esta afirmación de SILVA SÁNCHEZ parece la claudicación de un sistema que sigue la estructura de la dogmática por todas sus ventajas y, para nosotros, una excepción al respeto del principio de igualdad. Quizás sea en estos casos, justamente, donde tiene sentido seguir aferrado a la dogmática, porque aquí es donde se ve su fuerza y sentido con mayor claridad. De hecho, el estado de sospecha también comunica, y (casi) nadie está dispuesto a sancionar sólo por ello. Las conductas preparatorias o la peligrosidad del sujeto también comunican y (casi) nadie está dispuesto simplemente por ello a penar. Siempre se debe pasar por el filtro de la legitimidad ${ }^{117}$.

\section{CONCLUSIÓN}

La dogmática ha desarrollado y discutido durante años acerca de los presupuestos de un castigo legítimo, con resultados ostensiblemente positivos. Sin embargo, su vinculación con la determinación de la pena no ha tenido lugar sino en los últimos años.

La vinculación de la dogmática a la determinación de la pena ya debió tener lugar con la idea de la «culpabilidad como límite máximo», pues para saber cuál era el máximo se debía tener claro que contaba para la «culpabilidad». Pero un esfuerzo más fuerte surge de la idea de igualdad, que además de su valor moral inmanente evita fundamentaciones encubiertas de pena. Asimismo, con esta teoría se maximiza la posibilidad del sujeto de desarrollar su plan de vida debido a que puede conocer con cierta precisión las consecuencias de sus actos.

Si esto se acepta, si se considera correcto respetar el principio de igualdad, entonces cada segmento de pena sólo puede fundamentarse en criterios legítimos en base a los argumentos dogmáticos. Qué debe contar como castigo legítimo y qué no es un tema

116 SILVA SÁNCHEZ (n. 19), 9, 11 y ss.

117 Como afirma(ba) JAKOBS: «Naturalmente es perturbador saber que varias personas han concertado un delito [o que obran por ciertas motivaciones]; pero también perturba saber que alguien está reflexionando sobre la ocasión favorable para cometerlo o que alguien prepara con precisión, como autor único su comisión; a pesar de ello, las dos variantes de actos preparatorios últimamente citados están, en todo caso, exentas de pena...». Cfr., «Criminalización en el estadio previo a la lesión de un bien jurídico», en Estudios de Derecho penal, Madrid: UAM CIVITAS, 1985, 293, 306.

${ }_{118}$ Cfr. mi tesis doctoral, en elaboración, Los motivos en la determinación de la pena. 
arduo. La inmensa bibliografía al respecto lo demuestra. Lo importante aquí es lo siguiente: no se pueden fundamentar segmentos de pena sin recurrir a las categorías dogmática con el consiguiente esfuerzo argumental. No se puede remitir a necesidades preventivas, de la índole que sean, como un argumento suficiente, ni para agravar ni para atenuar la pena.

Es posible que, por ejemplo, los motivos cuenten para la determinación de la pena ${ }^{118}$, pero la argumentación deberá ser más sofisticada que la simple remisión a la manipulable «necesidad de pena» que se desentiende del merecimiento y de la necesidad moral de una distribución equitativa del castigo. De la imposibilidad de esa simple remisión se trata este trabajo. 
